\title{
$\nabla$ \\ Biogenic Synthesised Nanoparticles and its Role in Solanum Lycopersicum's Disease Management
}

\section{IJCRR}

Section: Healthcare

ISI Impact Factor

(2019-20): 1.628

IC Value (2019): 90.81

$\operatorname{SJIF}(2020)=7.893$

(c) (7) (8)

Copyright@IJCRR

\section{Maheshwari MS'1, Saritha V'ㄹ, Gopenath TS ${ }^{3}$, Kanthesh BM ${ }^{1}$}

'Division of Biotechnology, Faculty of Life Science, JSS Academy of Higher Education \& Research, Mysore; 'Department of Biotechnology, JSS College for Women (Autonomous), Mysore; ' ${ }^{3}$ Division of Molecular Biology, Faculty of Life Science, JSS Academy of Higher Education \& Research, Mysore.

\section{ABSTRACT}

Objective: We evaluated biogenic synthesized nanoparticle (NPs) from plant extracts and their role was studied in Solanum Lycopersicum.

Background: Several disease-causing organisms (pathogens) can infect Solanum Lycopersicum(Tomato). The most common diseases that affect tomatoes are caused by various fungi, bacteria, and viruses. The utility of plant extracts for NPs synthesis has various advantages such as accessibility and safety when handling.

Methods: We review bacterial diseases of tomatoes, the role of medicinal plants to control diseases. The study also includes the green synthesis of NPs and their application to control phytopathogens in Solanum Lycopersicum.

Results: This review critically assesses the role of medicinal extracts synthesized different NPs to control phytopathogens in tomato, application of NPs in tomato plant disease, antimicrobial studies in detail.

Conclusion: The need for environmental non-toxic synthetic protocols for NPs synthesis leads to the developing interest in biological approaches that are free from the use of toxic chemicals as by-products. Hence, there is an increasing demand for green nanotechnology. We discussed the role of many medicinal plant extracts to control phytopathogens and their applications in tomatoes.

Key Words: Solanum Lycopersicum, Nanoparticles, Phytopathogen, Bacteria, Antimicrobial, plant extracts

\section{INTRODUCTION}

Agriculture plays an important role in being the backbone of the economic system of a country, with $60 \%$ of the population depending on livelihood. An employment opportunity is provided by agriculture along with food and raw material supply. India has been bestowed with a good climate suitable for growing many kinds of fruits, vegetables, spices, and nuts with an immense nutritional benefit for mankind. Vegetables are important sources of many nutrients, dietary fibre, vitamins, potassium, and naturally low in fats and calories. Most of the vegetables have all these properties and tomato is considered one among them.

Tomato (S.lycopersicum) belonging to the Solanaceae family and the genus Solanum is one of the most important vegetable crops after potato. Because of its widespread and health-promoting compounds, it is the model organism for research. ${ }^{1}$ Tomato cultivation in India is 814000 ha during $2018-19$, and the production is $20515000 \mathrm{MT}$ (metric tons), by the Indian farmers an average production of tomato is about 25.2 tones/ha. This may vary depending on the season, region, and diseases. Major limiting factors towards the decreased productivity of to matoyield are diseases caused by bacteria, fungi, viruses, nematodes, insect pests, and viroids ${ }^{2}$. Major bacterial diseases are Bacterial Canker, Bacterial Wilt, Bacterial Spot, and Bacterial Speck. The most common fungal diseases are Anthracnose, Fusarium wilt, Powdery mildew, Late blight, Curly top viral disease, and Root-knot by nematodes. One of the major reasons for the decrease in tomato yield, hence we require a sustainable approach for the management of plant disease. Different chemical methods have been employed to control pathogens that may be hazardous to the environment. ${ }^{2}$ Even though various biological methods are employed,

\section{Corresponding Author:}

Dr. Kanthesh M Basalingappa, PhD., Assistant professor, Division of Molecular Biology, Faculty of Life Sciences, JSS Academy of Higher Education \& Research, Mysore-570015; Email: kantheshmb@jssuni.edu.in

ISSN: 2231-2196 (Print)

Received: 07.12 .2020
ISSN: 0975-5241 (Online)

Revised: 03.02 .2021
Accepted: 26.03 .2021
Published: 05.07 .2021 
they have their limitations. Therefore, a sustainable safe strategic environmentally friendly method is required. The use of NPs is one such safe method. The advantage of the opting NPs is that the reagents used in the synthesis are not hazardous and making them eco-friendly and effective.

Nanotechnology is an evolving field of science that involves the manipulation of matter at the nano-scale level to create NPs. NPs can be defined as any solid particle ranging in size from $1-100 \mathrm{~nm}^{3}$ There are various studies carried out that help us understand the importance of physicochemical properties of NPs that aid in designing NPs that control the accumulation and targeted disease treatment. NPs have tremendous applications in various industries including- electronics, chemicals, agriculture, environmental, pharmaceuticals, optical, ceramics, food processing and storage, water treatment, and so on. NPs can be metallic mostly made of the following metals. Silver is the most widely studied and used NPs as it is a very effective anti-microbial agent, also it is used in various other industries. ${ }^{4}$ Gold NPs are used in immunochemical methods for the detection of various protein interactions. Alloys exhibit different properties compared to their component and these have been exploited to produce NPs with wide applications. Metal oxide NPs have also been synthesized with various strategies and possess wide application in detecting harmful gases, solar cells, electroanalysis for the detection of biomolecules, water treatment as certain metal oxide NPs are excellent adsorbents and so on. ${ }^{5}$ Awareness received towards the biogenic synthesized NPs is because of the eco-friendly nature of NPs as well as low toxicity and biostability. Instead of using chemicals against pathogens, we can choose a better method to establish an eco-friendly environment.

To build a safe environment free from toxins, a safe approach to 'Biosynthesis' or 'Green synthesis' is required. Green synthesis of the NPs can be achieved by the utilization of bacteria, fungi, algae, and plant extracts. The utility of plant extracts for NPs synthesis has various advantages such as accessibility and safety when handling. These products are known as biogenic NPs. ${ }^{6}$ Various medicinal plant extracts are now used to treat chronic illnesses like diabetes, cancer, and even neurodegenerative disorders like Alzheimer's. Different medicinal plants were used to synthesize NPs thus incorporating the medicinal property of the plant into the biosynthesized NPs. Plants like Piper longum, Plumeriarubra, Crataevanurvala, Nigella sativa have been utilized to synthesize silver NPs(AgNPs). ${ }^{7}$ The perpetual contribution of people in medicinal plant usage has led to the present-day sophisticated processing and their use as drugs.

\section{BACTERIAL DISEASES IN TOMATO}

Tomato is prone to numerous bacterial diseases. Since bacterial pathogens double their population under favourable environmental conditions and colonize in the internal spaces of plants, it is not easy to control bacterial diseases. ${ }^{8}$ Based on their scientific and economic importance, the ten most important bacterial plant pathogensare Pseudomonas syringaepathovars, Ralstoniasolanacearum, Agrobacteriumtumefaciens, X.oryzae pv. oryzae, X.campestrispathovars, X.axonopodispathovars, Erwiniaamylovora, Xylellafastidiosa, Dickeya (dadantii and solani), and Pectobacteriumcarotovorum. ${ }^{9}$ The most common bacterial diseases are bacterial wilt (Ralstoniasolanacearum), bacterial spot (X.campestrispv.vesicatoria), bacterial canker (Clavibactermichiganensissubsp. Michiganensis $(\mathrm{Cmm})$ and bacterial speck (P.syringaepv. tomato). Cmm which causes the Bacterial canker of tomato is a gram-positive actinomycete. Bacterial canker has been considered as a devasting bacterial disease leading to less production of tomato..$^{10}$ Contaminated soil, plant debris, and seeds can be the major reason for systemic infections caused by $\mathrm{Cmm}$. At the early stage of infections fruit quality and yield may be affected leading to the death of the plant. ${ }^{11}$ At a temperature range of $25-30^{\circ} \mathrm{C}$ with neutral to slightly alkaline $\mathrm{pH}$ on nutrient glucose broth medium the causative agent of bacterial canker, Cmmgrows better ${ }^{12}$. Bacterial canker in tomato caused by Cmma threat that affects productivity. Mechanism of pathogenicity can be studied where transcriptional regulators and virulence factors play a key role and understanding the host bacterial interaction aid in developing new resistant varieties. ${ }^{11}$ Despite management and breeding efforts, Bacterial canker is the most dangerous bacterial disease with severe outbreaks. Bacteria first spread throughout the plant and then the symptoms are visible which is difficult to control, either by removing the diseased plant or by the chemical treatment. ${ }^{12}$ R.solanacearum, a soil-borne bacteria causative agent of Bacterial Wilt, a serious tomato disease that affects production in major climatic regions of the world. ${ }^{14}$ The isolation of these bacteria revealed the presence of sucrose and the pathogen dependency on sucrose for its virulence on vegetable crops like tomato and potato. During summer maximum yield loss occurs and the major impact of bacterial wilt on tomato is seen in Karnataka, Madhya Pradesh, West Bengal as well as Maharashtra.R.solanacearum a gramnegative $b$-proteobacteriumcauses bacterial wilt in food crops like tomato, potato, ginger, and banana along with other plant species. Since the bacteria live in soil and weed hosts for many years it is difficult to control by chemicals. ${ }^{15}$ Because of its systemic action, R.solanacearum affects the tomato plants at the reproductive as well as vegetative stage causing bacterial wilt that is difficult to control by using chemicals.

Another important disease is bacterial spot caused by four species of Xanthomonas:

X.euvesicatoria, X. vesicatoria, X. perforans, and X. gardneri in tomato, by causing lesions on fruits which decreases the quality of fruit and also resulting in severe yield loss. ${ }^{16}$ $X$. euvesicatoria, $X$. perforans and $X$. vesicatoria were the 
important pathogenic species identified by the analysis of phylogenetic and biochemical methods. When pathogenicity was assessed in Australian tomato, chilli, and capsicum plants, they showed at least five Xanthomonas species that cause bacterial leaf spot. ${ }^{17}$ In Iran, the Bacterial spot in tomato is caused by $X$. perforans along with $X$. axonopodisand X. campestri.s $^{18}$.X.campestrispv. vesicatoria may not be the only pathogen that causes lesions on tomato leaves, several other pathogens like $X$. campestrispv. raphani and $X$. arboricola are also involved. To understand the pathogen and its effect, the mechanism of biological and epidemiological aspects of the pathogen plays the main role. X. perforans that infects the only tomato causing bacterial spot was also seen and identified from pepper plants that showed similar symptoms on leaves and fruits. The bacterial spot spreads through the air, water, symptomatic plant debris, and seeds ${ }^{19}$ The bacterial spot in tomato, caused by X.campestrispvvesicatoria was isolated in many countries, this was supported by the cultural, morphological, and biochemical tests. ${ }^{20}$

P.syringaepv. Tomato, a seed-borne pathogen causes bacterial speck on tomatoes. A relatively low temperature i.e., $12^{\circ} \mathrm{C}$ $-25^{\circ} \mathrm{C}$, and high humidity are required for the occurrence of disease. At early stages, on tomato leaves minute dark brown spots surrounded by yellow halo appeared, and at later stages burning of leaf margins, stunted growth appears. Infected seeds and contaminated weeds can be one of the main reasons for the spread of the bacterial pathogen, P.syringaepv tomato that causes bacterial speck in tomato. ${ }^{19}$ Changes adopted in the cropping system create a suitable environment for pathogens, for example, P.syringae causative agent of bacterial speck, normally known to be found in the open field can also be frequently seen in the protected field. ${ }^{14} P$. syringae causative agent of bacterial speck encodes a sigma factor $\mathrm{AlgU}$ that controls those genes that express alginate biosynthesis. It was found $\mathrm{Alg} U$ can be one of the major virulence factors for P.syringaepv tomato DC3000. ${ }^{21}$ Seedling stage infection caused by P.syringaepv. Tomato leads to decreased quality and loss of yield. Bacterial speck causing significant damage to tomato has led to the development of many biological control measures ${ }^{22}$. Since Chemicals usage releases toxic substances resulting in a hazardous environment and increased demand for safe food has led to the development of an alternative and eco-friendly approach to gain pathogenfree plants. A biological approach is essential for the welfare of mankind.

\section{ROLE OF MEDICINAL EXTRACTS TO CONTROL PHYTOPATHOGENS IN TOMATO}

Most of the currently available drugs are directly or indirectly derived from a plant source. Sumerian clay slab encryption is one of the oldest written pieces of evidence for using medicinal plants to prepare various drugs which is about 5000 years old. Even Indian Vedas, Chinese literature, Ebers
Papyrus mentions treatment using plants and their parts. Over time the importance of medicinal plants decreased but since the early $20^{\text {th }}$ century, the need for natural compounds increased due to adverse side effects from synthetic compounds. The shift from single target to multidrug target approach for complex diseases offers a platform for herbal formulations. Phytochemical studies on various medicinal plants show the presence of various secondary metabolites that possess a wide range of pharmacological activities like anti-inflammatory, anti- cholinesterase, hypolipidemic, antioxidant, anti-microbial, etc. Aqueous and organic extracts prepared from leaves, stems, and fruits of WithaniasomniferaLshowed maximum antifungal activity against the target pathogen Fusariumoxysporum f. sp.radicis- lycopersici (FORL)causal agent of Fusariumcrown and root rot which is one of the devasting diseases in tomato. ${ }^{23}$ The first report on the in vitro antifungal activity of chloroform, ethyl acetate, and butanol extracts from $W$. somniferaleaves, stems, and fruits, against FORL. Results showed that $W$. somnifer$a$ extracts exhibited a significant antifungal effect against this pathogen. Bioactive compounds from $W$. somniferaextracts, involved in the registered antifungal activity, could serve as a potential source of naturally derived fungicides once their efficacy is proved in vivo on FORL-infected tomato plants. ${ }^{23}$ The potency of aqueous extracts of TageteserectaL. (marigold) in controlling bacterial speck disease in tomato plants. The experimental design consisted of two groups of 50 plants each: group 1-sprayed with sterile water (control); and group 2 - sprayed with the marigold extract. Spraying was performed under aseptic conditions at the third node from the base of each plant. The observations indicate that marigold extract could be a promising biopesticide ${ }^{24}$. Trichodermaviridae was most effective in the reduction process of A. solaniand T. harzianum. T. viridaealso showed the highest inhibition in volatile and non-volatile trials. Six plants extract viz., Adhatodavasica(Nees), Azadirachtaindica(A Juss),Ocimujm sanctum (L), Allium sativum (L), Datura metal (Linn), and Zingiberofficinale were selected to evaluate their in-vitro efficacy of 5\%,10\% and $20 \%$ concentration against the $A$. solani. A. sativumwas the most effective one against $A$. solani, followed by $A$. indica ${ }^{25}$. All these studies show the wide usage of medicinal extracts and their properties which can be used to build a safe environment.

\section{GREEN SYNTHESIS OF NPS}

NPs can be synthesized using various methods-physical, chemical, biological as well as hybrid techniques. There are two main approaches in the synthesis of NPs the- top-down and bottom-up. The classical top-down approach starts from bulk material and is scaled down to parts and finally to nanoscale details. On the contrary, the bottom-up approach includes the assembly of atoms to form larger nanoscopic structures. This includes physical and chemical methods. Physicalmethods mainly are based on top-down strategy. 
These methods break down the bulk counterpart by using mechanical pressure, high energy radiations, electrical energy, evaporation, etc to produce fine NPs. These methods are useful as they produce uniform monodisperse NPs but are less economical as they produce ample waste. Chemical methods are under the bottom-up category of NPssynthesis and they are not eco-friendly because of some toxic substances. ${ }^{26}$ Green syntheses is an alternative and safe approach to synthesize NPs using biological materials like microbes, plant extracts, or by-products of organisms like proteins, lipids by using various biotechnological tools. This bio-assisted method provides low-toxic, cost-effective, environmentally friendly products. NPs synthesized via bioinspired methods offer very interesting applications in biomedicine and related field. ${ }^{27}$ Plants have been an exemplary source of drugs since ancient times.

The utility of plant extracts as reducing agents has various advantages such as Accessibility and safety when handling. NPs can be metallic mostly made of the following metals like gold, silver, etc. Gold NPs are used in immunochemical methods for the detection of various protein interactions. Alloys exhibit different properties compared to their component and these have been exploited to produce NPs with wide applications. Metal oxide NPs have also been synthesized with various strategies and possess wide application in detecting harmful gases, solar cells, electroanalysis for detection of biomolecules, water treatment as certain metal oxide NPs are excellent adsorbents and so on. ${ }^{5}$ Biosynthesis of metal NPs using medicinal plant extract is a safe, economical method, which protects mankind and helps to maintain a green environment.

\section{ROLE OF MEDICINAL EXTRACTS SYNTHESIZED NPS TO CONTROL PHYTOPATHOGENS IN TOMATO}

A study showed that candidate antibacterial agents made from copper oxide NPs loaded onto the surfaces of graphene oxide sheets to form the series GO-Cu NPs. Antibacterial activity results indicated that GO- $\mathrm{Cu}$ NPs had a 16-times higher antibacterial activity. ${ }^{22}$ The study on antimicrobial screening of silver NPs (AgNPs) revealed strong inhibition of gramnegative and gram-positive bacteria as well as various fungal species. The effective inhibition of both gram-negative and gram-positive bacteria by AgNPs derived from Moringaoleiferaleaf extracts is of great significance as it demonstrates their broad-spectrum antibacterial activity. ${ }^{3}$ A sustainably synthesized copper oxide NPs (CuONPs) using papaya leaf extracts was obtained to study the bactericidal activity against Ralstonia solanacearum, where the results showed that CuONPs possessed a strong antibacterial activity, by preventing biofilm formation, showing reduced swarming motility, and also ATP production was altered. Transmission electron microscopy (TEM) results revealed that the interaction of CuONPs on bacteria caused cytomembrane damage. ${ }^{28}$
This study continued with green Se NPs (selenium NPs) are formed by simple mixing of Withaniasomnifera ( $W$. somnifera) leaves extract and selenious acid $\left(\mathrm{H}_{2} \mathrm{SeO}_{3}\right)$ solution. The synthesized Se NPS by FT-IR spectrum confirms the presence of functional groups which were associated with bioactive molecules. The combination of phytocompounds and NPS serves an efficient role in its multifaceted pharmacological properties ${ }^{29}$. Cobalt NPs were synthesized by using Drumstick tree leaves. The NPS was also characterized with the help of many different techniques which are UltravioletVisible(UV-VIS) spectroscopy, Fourier transforms infrared (FTIR) spectroscopy and Scanning electron microscopy (SEM). The characteristic UV peak of Co NPs was obtained. Phytochemicals play an important role as capping and reducing agents in nano synthesis. AgNPs obtained from the Clitoriaternateand Solanumnigrumhave very strong inhibitory action against Pseudomonas aeruginosa followed by Staphylococcus aureus, Escherichia coli, and Streptococcus viridans.

The AgNPs of Clitoriaternateashowed higher activity than the AgNPs of Solanumnigrumagainst nosocomial pathogens. This study showed a simple, rapid, and economical route to synthesize silver NPs. Gold NPs with an average size of $32.96 \pm 5.25 \mathrm{~nm}$ were synthesized using Garciniamangostanacommonly known as mangosteen fruit peel. ${ }^{30}$ Biosynthesis of copper NPs, gold-iron, and silver iron core-shell NPs using extracts of Punicagranatumwas also reported. ${ }^{31}$ and characterized using UV-VIS spectroscopy, FTIR, and TEM. The synthesis of NPs was confirmed by UV-VIS spectrophotometer, X-ray diffraction (XRD), and SEM. Their observation through particle size analyzer (PSA) and TEM showed dominant spherical morphology with an average diameter of $5 \mathrm{~nm} .{ }^{32}$ The green synthesis shows that the environmentally benign and renewable sources ofMoringaoleifera, Murrayakoingii, and Ocimumsanctumare used as effective reducing agents for the synthesis of AgNPs. This biological reduction of AgNPs would be a boon for the development of a clean, non-toxic, and environmentally acceptable green approach to produce AgNPs, involving organisms even ranging to higher plants. The formed AgNPs are highly stable and have significant activity against diarrhoea bacterial strains (Escherichia coli, Staphylococcus aureus). ${ }^{33}$ In another work, it was demonstrated that chitosan NPs (CNPs) have significant antifungal activity $C$. gelosporidies, $P$. capsici, $S$. sclerotiorum, F. oxysporum, and G. fujikori, phytopathogens of tomato. ${ }^{34} \mathrm{CNPs}$ can be effectively used against plant phytopathogenic fungi ensuring a plethora of positive outcomes ranging from antifungal, antibacterial activities, plant growth promotion, biocidal activities, and reduction in harmful effects to humans and the environment due to chemical fertilizers. The study ${ }^{35}$ shows that biosynthesized NPs can be used as an alternative to conventional fungicides and become helpful in minimizing environmental pollution. 
Meliaazedarach extract-AgNPs (MLE-AgNPs) is used as an eco-friendly approach to control the Fusarium wilt of tomatoes at various concentrations by suppressing the growth of $F$. oxysporum. MLE-AgNPs have shown strong potential to restrain the fungal population both in lab and field trials in a dose-dependent manner. The application of NPs on preinfected roots of tomato plants successfully reduced the wilt by increasing the resistance of the host plant and enhancing the growth parameters of tomato seedlings. The study carried by, ${ }^{36}$ to investigate the antifungal activity of silver NPs synthesized using Citrus sinensis peel extract against fungal phytopathogens isolated from diseased tomato. The isolated fungal phytopathogensIrenopsis, Diaporthe, and Sphaerosporiumsppobtained the highest antifungal activity with an inhibition rate of 82,46 , and $57 \%$ respectively. This research indicated that silver NPs were effective in controlling fungal isolates.

\section{CONCLUSION}

Several species (pathogens) that cause disease can infect S.lycopersicum L (tomato) and cause disease. Various fungi, bacteria, and viruses cause the most common diseases that affect tomatoes. Here, we summarised the bacterial diseases and the green synthesis of NPs in a tomato plant. Under favourable environmental conditions, bacterial pathogens double their population and colonize the internal spaces of tomato plants; bacterial diseases cannot easily be managed. Several studies show that to control plant pathogens including bacteria, fungi, and viruses, biogenic synthesized NPs using microbes and plant extracts without hazardous chemicals are promising. There are various benefits to the usefulness of plant extracts for NPs synthesis, such as accessibility and protection during handling. There is also an increasing demand for green nanotechnology; the need for non-toxic synthetic environmental protocols for NPs synthesis contributes to a growing interest in biological approaches that are free from the use as by-products of toxic chemicals. We also discussed the role of many extracts from medicinal plants in regulating phytopathogens and their tomato applications. Finally, this review critically assesses the function of synthesized medicinal extracts of various NPs in the control of tomato phytopathogens, the application of NPs to tomato plant disease, and extensive antimicrobial studies.

Disclosures: The authors declare that there is no conflict of interest in this article's content.

\section{Conflict of Interest: Nil}

\section{Source of Funding: Nil}

Author Contributions: Maheshwari MS (MMS) and Kanthesh BM (KBM) conceptualized the study. Maheshwari MS (MMS), Saritha V (SV), and T. S. Gopenath (TSG) drafted the Manuscript. Maheshwari MS (MMS), T. S. Gopenath (TSG), and Kanthesh BM (KBM) helped with the Manuscript and Discussion.

\section{ACKNOWLEDGEMENT}

The authors would like to express gratitude towards the institute of JSS Academy of Higher Education \& Research and also JSS College for Women, Mysore, for providing the necessary help for the research work. The authors are also grateful to authors/editors/publishers of all those articles, books, and journals from where the literature for this article has been reviewed and discussed.

\section{REFERENCES}

1. Quinet M, Trinidad A, Fernando JY, Remi BG, Servane B, Martinez JP, Stanley L, Tomato Fruit Development and Metabolism: a review. Front PlantSci. 2019 Nov; 10: 1-23.

2. Mandal AK, Maurya PK, Dutta S, Chattopadhyay, A Effective Management of Major Tomato Diseases in the Gangetic Plains of Eastern India through Integrated Approach. J Agric Res Technol. 2017 Aug; 10(5): 109-16.

3. Moodley JS, Suresh BN, Karen P, Sershen, Patrick G, Green synthesis of silver Nanoparticles from Moringaoleifera leaf extracts and its antimicrobial potential. Adv Nat Sci-Nanosci. 2018 Mar; 9: 1-10.

4. Ahmed S, Ahmad M, Swami BL, Ikram S, A review on plants extract mediated synthesis of silver nanoparticles for antimicrobial applications: A green expertise. J Adv Res. 2016 Jan; 7(1): $17-28$

5. Hasan S, A review of Nanoparticles: their synthesis and types. Res J RecentSci. 2015 Feb; 4: 9-11.

6. Singh J, Dutta T, KimKH, RawatM, SamddarP, Kumar P, Green synthesis of metals and their oxide Nanoparticles: applications for environmental remediation. J Nanobiotech. 2018 Oct; 16(1): $2-24$.

7. Christy J, Dharaneya D, Vinmathi V, Justin PJ, A Green nanobiotechnological approach for the synthesis of silver Nanoparticles using the seed coat of Tamarindusindica, the study of its antibacterial and anticancer activity. Int J Pharm PharmSci. 2015 Sep; 7(13): 192-94.

8. Sundin GW, Luisa FC, Xiaochen Y, Ching-hong Y, Review: Bacterial disease management: challenges, experience, innovation, and prospects. Mol PlantPathol. 2016 May; 17(9): 1506-18.

9. Yuliar, Yanetri AN, Toyota K, Mini review: Recent Trends in Control Methods for Bacterial Wilt Diseases Caused by Ralstoniasolanacearum. Microbes Environ. 2015 Feb; 30 (1): 1-11.

10. Chalupowicz L, Barash I, Reuven M, Dror O, Sharabani G, Gartemann KH, Echenlaub R, Sessa G Manulis SS, Differential contribution of Clavibactermichiganensis ssp. michiganensis virulence factors to systemic and local infection in tomato. Mol Plant Pathol. 2017 Apr; 18(3): 336-46.

11. Nandi M, Macdonald J, Liu P, Weselowski B, Yuan ZC, Review: Clavibactermichiganensis ssp. michiganensis: bacterial canker of tomato, molecular interactions, and disease management. Mol PlantPathol. 2018 Mar; 19(8): 2036-50.

12. Singh G, Bharat NK, Studies on Bacterial Canker (Clavibactermichiganensissubsp. michiganensis) of Tomato (Solanumlycopersicum). Int J Curr Microbiol Appl Sci. 2017 Sep;6(9): 317-23. 
13. Sen Y, Wolf JV, Richard VG, Heusden S, Bacterial canker of tomato: current knowledge of detection, management, resistance, and interactions. The American PhytopatholSoc Plan Dis. 2015 Oct; 99(1): 4 -13.

14. Yuqing W, Yaxian Z, Zhipeng G, Wencai Y, Breeding for Resistance to Tomato Bacterial Diseases in China: Challenges and Prospects. Hortic Plant J. 2018 Aug; 4 (5): 193-207.

15. Imada K, Sakai S, Kajihara H, Tanaka S, Ito S Magnesium oxide Nanoparticles induce systemic resistance in tomato against bacterial wilt disease. Plant Pathol J. 2016 Sep; 65: 551-60.

16. Sharma S, Bhattarai K, Review: Progress in Developing Bacterial Spot Resistance in Tomato. Agronomy. 2019 Jan; 9(26): 1-11.

17. Roach R, Mann R Gambley CG, Shivasand G, Rodoni B, Identification of Xanthomonas species associated with bacterial leaf spot of tomato, capsicum, and chilli crops in Eastern Australia. Eur J PlantsPathol. 2017 July; 150: 595-08.

18. Osdaghi E, TaghaviSM, Hamzehzarghani H, FazliarabA, Lamichhane JR, Monitoring the occurrence of tomato bacterial spot and range of the causal agent Xanthomonasperforans in Iran. Plant Pathol. 2017 Nov; 66(6): 990-02.

19. Penazova E, Dvorak M, Ragasova L, Kiss T, Pecenka J, Cechova J, Eichmeier, A Multiplex real-time PCR for the detection of Clavibactermichiganensissubsp. michiganensis, Pseudomonas syringaepv. Tomato and pathogenic Xanthomonasspecies on tomato plants. PLOS ONE. 2019 Jan;15(1): 1-15.

20. Ogolla FO, Neema DB. Cultural, Morphological and Biochemical identification of XanthomonasSpp the Causative Agent of Bacterial Leaf Spot in Tomatoes in Wanguru, Mwea, Kirinyaga County, Kenya. Int J Res Innova Appl Sci. 2019 Jan; 4(4): 44-8.

21. Markel E, Stodghill P, Bao Z, Myers CR, Swingle BS, AlgU Controls Expression of Virulence Genes in Pseudomonas syringaepv tomato DC3000. J Bacteriol.2016 Sept; 198: 2330-44.

22. Yadong L, Desong Y, Jianghu C Graphene oxide loaded with copper oxide Nanoparticles as an antibacterial agent against Pseudomonas syringaepv. Tomato. The Roy SocChem. 2017 July; 7:38853- 60 .

23. Nefzil A, Abdallah RA, Khiareddine HJ, Saïdana SM, Rabiaa $\mathrm{H}$, Mejda DR Antifungal activity of aqueous and organic extracts from Withaniasomnifera L. against Fusariumoxysporum f. sp. radicis-lycopersici. J MicrobBiochem Techno. 2016 Mar; 8(3): 144-50.

24. Goel NA, Prabir KP, Biocontrol of bacterial speck of tomato by aqueous extract of Tageteserecta. J Plant Protect Res. 2017 Nov; 57(4): 361-69.

25. Roy CK, Akter N, Sarkar MK, Uddin MP, Begum N, Zenat EA, Jahan MA, Control of Early Blight of Tomato Caused by
Alternariasolaniand Screening of Tomato Varieties against the Pathogen. The Open Microb J. 2019 Jan; 3: 41-50.

26. Nadaroglu H, GungorAA, Selviİnce, Synthesis of Nanoparticles by Green Synthesis Method International Journal of Innovative Research and Reviews. IntJ Food AgricVeter. Sci2017 Dec; 2 (2):173-82.

27. Agarwal H, VenkatKumar S, Rajeshkumar S, A review on green synthesis of zinc oxide Nanoparticles -An eco-friendly approach. Res Effic Technol. 2017 April;3: 406-13.

28. Juanni C, Shuyu M, Zhifeng X, Wei D, Various antibacterial mechanisms of biosynthesized copper oxide Nanoparticles against soil-borne Ralstonia solanacearum. The Roy SociChemAdvan. 2019 Jan; 9: 3788-99.

29. Venkatesan A, Sujatha VL, Green synthesis of Selenium Nanoparticles using leaves extract of Withaniasomnifera and its biological applications and photocatalytic activities. Bio-Nano Sci. 2019 Mar; 9: 105-16.

30. Lee XK, Shameli K, Miyake M, Noriyuki K, Nurul B, Ahmad BK, Shaza EB, Yen PY, Green synthesis of gold Nanoparticles using Garciniamangostana fruit peel. J Nanomat. 2016; 2: 1-7.

31. Kaura P, Rajesh T, Himanshu M, Anju M, Ashok C, Biosynthesis of biocompatible and recyclable silver/iron and gold/iron coreshell Nanoparticles for water purification technology. Biocatal Agric Biotechnol. 2018 Apr; 14: 189-97.

32. Bansal P, Kaur P, Duhan JS, Biogenesis of silver Nanoparticles using Fusarium pallidoroseum and its potential against human pathogens. Ann Biol. 2017 June; 33 (2): 180-85.

33. Masese OB, Hemachitra P, Deepa R, Senthamarai VS, Synthesis of silver nanoparticles and its antibacterial activity from Moringaoleifera, Murrayakoingii and Ocimum sanctum against E.coliandS.aureus.Der Pharm Lett. 2016 June; 8(10): 150-60.

34. Wook $\mathrm{OH}, \mathrm{Se} \mathrm{CC}$, Murugesan $\mathrm{C}$, Preparation and in vitro characterization of chitosan Nanoparticles and their broad-spectrum antifungal action compared to antibacterial activities against phytopathogens of tomato. Agron. 2019 Jan;9(1): 1-12.

35. Ashraf H, Anjum T, Riaz S, Naseem S, Microwave-assisted green synthesis and characterization of silver Nanoparticles using Melia azedarach for the management of Fusarium wilt in tomato. Front Microbiol. 2020 Mar; 11: 1-22.

36. Obiazikwor OH, Shittu HO Antifungal activity of silver nanoparticles synthesized using Citrus sinensis peel extract against fungal phytopathogens isolated from diseased tomato (Solanumlycopersicum L). BiolSciPharma Res. 2018 Dec; 6(3): 30-8. 